Religare, ISSN: 19826605, v.15, n.1, agosto de 2018, p.174-196.

\title{
Estágio supervisionado: uma perspectiva acerca das contribuições técnicas, legais e pedagógicas para a formação do professor de ensino religioso
}

\author{
Supervised internship: a perspective about the technical, \\ legal and pedagogical contributions for the formation of the \\ teacher of religious education
}

Marinilson Barbosa da Silva ${ }^{1}$

Thiago R.S de Souza Guedes²

\section{Resumo}

Esta investigação teórico-documental busca analisar as perspectivas do Estágio Supervisionado em docência, mais especificamente quanto ao processo de construção da identidade profissional do ser professor de Ensino Religioso, levando-se em consideração a ligação entre teoria/prática e implicações acerca do Estágio Supervisionado no Curso de Licenciatura em Ciências das Religiões no contexto da UFPB. Neste sentido, prioriza-se o resgate histórico acerca do Estágio Supervisionado no Brasil, bem como os aspectos técnicos, legais e pedagógicos do mesmo, tratando-se assim de um encadeamento de exigências, prerrogativas e preceitos para os estagiários, como também para as entidades de ensino superior e os estabelecimentos escolares, onde se passa o estágio e suas contribuições para o futuro da profissão e do ser professor do Ensino Religioso.

Palavras-Chave: Estágio Supervisionado. Docência. Ciências das Religiões. Ensino Religioso.

\footnotetext{
${ }^{1}$ Graduado em Psicologia pela UFPB e Doutor em Educação pela Universidade Federal do Rio Grande do Sul - UFRGS; professor Associado pelo Departamento de Habilitações Pedagógicas (DHP) - Centro de Educação (CE) - da Universidade Federal da Paraíba (UFPB), atuando nos cursos de Pedagogia Presencial e a Distância (EAD); É também professor do Programa de PósGraduação em Ciências das Religiões (PPGCR).

${ }^{2}$ Mestrando em Ciências das Religiões, pela Universidade Federal da Paraíba - UFPB; Especialista -em Educação pela Universidade Estadual da Paraíba - UEPB; Graduado em Ciências dasReligiões pela Universidade Federal da Paraíba - UFPB; Graduado em Direito pelo Centro Universitário de João Pessoa - UNIPÊ; Graduado em Teologia pela Faculdade de Tecnologia, Ciências e Biotecnologia da CGADB - FAECAD.
} 
Religare, ISSN: 19826605, v.15, n.1, agosto de 2018, p.174-196.

\section{Abstract}

This theoretical-documentary research seeks to analyze the perspectives of the Supervised Internship in teaching, more specifically regarding the process of construction of the professional identity of being a teacher of Religious Education, taking into account the connection between theory / practice and implications about the Supervised Internship Degree in Religious Sciences in the context of UFPB. In this sense, priority is given to the historical recovery of the Supervised Internship in Brazil, as well as to the technical, legal and pedagogical aspects of the same, thus dealing with a chain of requirements, prerogatives and precepts for trainees, as well as for entities higher education and school establishments, where they pass the internship and their contributions to the future of the profession and to be a teacher of Religious Education.

Keywords: Supervised Internship. Teaching. Sciences of Religions. Religious Education.

\section{Introdução}

A perspectiva do Estágio Supervisionado (ES) em cursos de graduação/ licenciaturas em Ciências das Religiões com ênfase na formação de professores de Ensino Religioso (ER) como elemento preparatório e formador desses futuros professores na área, tem a sua história de percalços e dificuldades frente a realidade brasileira no que diz respeito aos aspectos técnicos, legais e pedagógicos, como será analisado neste estudo.

Desde a colonização até os tempos atuais, a temática é complexa e exige rigor reflexivo e crítico. Muitas dificuldades têm permeado a questão, desde o tempo da predominância de uma formação intimamente interligada somente a uma confissão religiosa, até ao momento atual de articulação ao respeito à diversidade religiosa. O Estágio Supervisionado deve contemplar um professor de ensino religioso que é, na escola e na sua comunidade, um mediador da própria questão religiosa, da espiritualidade, sendo assim, um promotor do diálogo inter-religioso e da busca pela ética e pela paz. Daí, a importância do professor de ensino religioso, pois ele torna-se um elo, uma espécie de interlocutor entre o elemento religioso presente na realidade social e a realidade 
Religare, ISSN: 19826605, v.15, n.1, agosto de 2018, p.174-196. pedagógica própria da escola e da comunidade (SILVA, 2011, p. 11)

De acordo com o texto referência para a Audiência Pública sobre as Diretrizes Curriculares Nacionais para o curso de graduação em Ciências da Religião, promovido pelo Conselho Nacional de Educação em Setembro de 2018, o mesmo afirma que:

Art. 2o $\mathrm{O}$ curso de graduação em Ciências da Religião Licenciatura, constitui-se como habilitação em nível de formação inicial para o exercício da docência do Ensino Religioso na Educação Básica.

§1ํㅡㄹ Compreende-se a docência em Ensino Religioso como a ação educativa sistemática e intencional baseada no reconhecimento da diversidade religiosa presente na sociedade brasileira e mundial.

$\S 2^{\underline{0}}$ A docência em Ensino Religioso adota a pesquisa e o diálogo como princípios mediadores e articuladores dos processos de observação, análise, apropriação e ressignificação dos conhecimentos religiosos elaborados historicamente por distintas culturas e sociedades.

§3 ${ }^{\text {o }} \mathrm{Na}$ docência do Ensino Religioso são abordados conhecimentos produzidos pelas diversas culturas, tradições religiosas e filosofias de vida a partir de pressupostos éticos e científicos, sem privilégio de nenhuma crença ou convicção, visando promover o reconhecimento da diversidade religiosa.

O texto ainda afirma que em se tratando do Estágio Supervisionado, o Artigo 7ํㅜ , inciso IV, diz que nos termos do Projeto Pedagógico do Curso, a integralização de estudos será efetivada por meio de estágio curricular (grifo nosso), a ser realizado ao longo do curso em todos os níveis da Educação Básica, de modo a assegurar aos graduandos experiência na docência em Ensino Religioso nos diferentes contextos escolares.

O Artigo 8o diz que o Estágio obrigatório do curso de Ciências da Religião inclui o desenvolvimento de atividades de observação, planejamento e docência nas diferentes etapas e modalidades da Educação Básica.

Conforme a Lei de Diretrizes e Bases da Educação Nacional - LDB 9.394/96, o Estágio Supervisionado é uma formalidade instituída em cursos de que tem por essência, ampliar a participação discente em atividades práticas que estejam 
Religare, ISSN: 19826605, v.15, n.1, agosto de 2018, p.174-196. ligadas com os conteúdos estudados em sala de aula, melhorando assim, a condição dos instrumentos pelos quais os docentes são formados. As atividades desempenhadas no momento que o estudante se encontra exercendo o estágio em uma unidade escolar, ganha com isto uma importância extraordinária e ao mesmo tempo imprescindível que pede o mercado atualmente: a oportunidade de desenvolver a experiência profissional docente. Podemos verificar que as atividades desempenhadas no momento em que o estudante estagia, são essencialmente importantes, por proporcionar para o estudante uma experiência de prospecção de realidade.

Januário (2008), certifica que é no momento em que o estudante frequenta o Estágio Supervisionado que ele contrai na prática o ofício de futuro professor e é através de suas visões e ações na rotina do estágio, que ele desenvolve no segmento educacional uma maior sensibilidade, tentando compreender que realidades permeiam as escolas e consequentemente o sistema educacional como um todo.

Para o autor, apesar de o Estágio Supervisionado nas licenciaturas ser um meio que consideramos fundamental na construção de uma identidade profissional docente de ser professor de Ensino Religioso no contexto de sala de aula, temos que reconhecer que o estudante por si só não é responsável pela formação de sua identidade docente. Existe toda uma conjuntura sócio-histórica, econômica e político-pedagógico que exige uma perspectiva formativa no contexto escolar que agregue uma contemporização com a diversidade que estão hoje nos mais diversos estabelecimentos escolares do nosso país, quer sejam eles confessionais ou não.

Filho (2010), acrescenta ainda que a experiência do estágio estão intimamente interligados entre o resgate da teoria e prática como processos indissociáveis, permitindo-se assim que se gere uma forte ligação entre as teorias absorvidas durante o andamento do curso e a prática. A prática aqui é entendida como um processo de prospecção de realidades, onde os estudantes vão se deparar com diferentes situações e projeções que farão parte do seu universo 
Religare, ISSN: 19826605, v.15, n.1, agosto de 2018, p.174-196.

escolar, acadêmico e pedagógico como futuros docentes em suas respectivas salas de aula.

Assim, o professor do Ensino Religioso tem a árdua tarefa de perpetuar na sociedade as práticas e conhecimentos adquiridos na academia sobre os mais diversos sistemas culturais religiosos, devendo assim construir um elo entre as mais diversas teorias e a prática visualizadas no âmbito do curso de graduação.

Nesse aspecto, o artigo procura resgatar uma perspectiva histórica acerca do Estágio Supervisionado no contexto brasileiro e suas implicações frente ao processo de construção da identidade profissional do ser professor de ensino religioso, culminando com uma breve e panorâmica reflexão acerca da Resolução CGCR 02/2011, que regulamenta o Estágio Supervisionado do curso de graduação em Ciências das Religiões da UFPB, como será abordado a seguir.

\section{Histórico do estágio supervisionado}

\subsection{Breve Histórico do Estágio Supervisionado}

O Estágio Supervisionado como experimentamos, passa a existir no Brasil fundamentalmente na década de 1930 com a ascensão da indústria brasileira, na égide do que ficou conhecido como "atividades escolares". As mais rudimentares letras jurídicas de regulamentação do estágio remontam ao decreto no 20.294 de 12 de agosto de 1931, das Leis Orgânicas de Ensino Industrial (DL 4.073/1942) e Comercial (DL 6141/1943), e que tinham como desígnio principal, o arremate das atividades do binômio ensino/aprendizagem, mas ainda assim era carente de uma legislação que dispusesse de maneira clara sobre seus objetivos a serem cumpridos por professores e estagiários.

Também como diretriz regulamentadora havia uma portaria, de Setembro de 1967, cujo número era 1002, estabelecida pelo Excelentíssimo senhor Ministro do Trabalho e Previdência, que instituiu nas empresas e entidades e como consequência no âmbito escolar a categoria de estagiário, criando assim uma relação de fato e de direito, estabelecendo direitos e obrigações para estes e para 
Religare, ISSN: 19826605, v.15, n.1, agosto de 2018, p.174-196.

com as unidades concedentes dos estágios. Apesar de tudo dizia que, entretanto, esta relação não estabelecia um vínculo de natureza empregatícia entre ambas as partes, mas sim que se tratava de uma relação de complementação da aprendizagem e de conhecimento in loco da rotina profissional a qual o jovem iria se submeter ao fim dos seus estudos. Mais precisamente em 13 de janeiro de 1972, foi criado o Programa Bolsa do Trabalho pelo Decreto no 69.927, que ampliou o estágio para os estudantes em todas as modalidades de ensino, ou seja, ensino médio ensino técnico, estabelecendo uma carga horária de no máximo quatro horas diárias e vinte horas na modalidade semanal e criou também uma relação direta entre o que era fornecido ao aluno em matéria de conteúdo em sala de aula e as atividades que eram desenvolvidas na rotina do estágio.

No dia 7 de dezembro de 1977 surgiu uma lei, a lei nº 6.494, regulamentada com o Decreto no 84.497 de 18 de agosto de 1982 que pôs fim nos debates que dizia respeito a constitucionalidade da Portaria nº 1.002/67 e estabeleceu a relação de estágio.

A Lei n⿳o 6.494/77 não foi bem recepcionada:

A Lei $\mathrm{n}^{\mathrm{o}}$ 6.494/77 não era tão rígida, proporcionando a contratação de muitos estagiários em fraude à lei, pois preenchiam os requisitos do contrato de trabalho. Na prática, o que existia era um subemprego disfarçado e o legislador não tinha os mecanismos para proteger o estagiário dessa prática. (MARTINS, 2012, p.35)

Enfim em 25 de Setembro de 2008, foi publicada a Lei nº 11.788, que acabou por revogar toda a legislação outrora citada e a partir deste momento ficou regulamentando os estágios dos estudantes no país. Essa lei foi um projeto de Lei no 473 de 2003, que intentava a incorporação de novos elementos na legislação brasileira, além de oferecer mais subsídios legais para os jovens que estavam em processo de se educarem, bem como instigar uma maior parte de empresas, 
Religare, ISSN: 19826605, v.15, n.1, agosto de 2018, p.174-196.

universidades e escolas para que elas viessem a criar programas de estágio, favorecendo uma significativa parte dos jovens.

\section{Função}

A função do Estágio Supervisionado é o fator central na relação. É o elo diferenciador entre o que é um estágio, e o que é uma atividade em que se tem uma relação de emprego. Nesse caso frustra-se em tudo a possibilidade de uma melhora substancial na atividade docente. Pois ao cair no laço de se parecer com uma relação de emprego a atividade desempenhada pelo estagiário cai nos vícios naturais impostos por uma mentalidade apenas mercantilista e em que nada tem haver com o real objetivo do Estágio Supervisionado, no caso das Ciências das Religiões. Vejamos então:

Não obstante o estagiário possa reunir, concretamente, todos os cinco pressupostos da relação empregatícia (caso o estágio seja remunerado), a relação jurídica que o prende ao tomador de serviços não é, legalmente, considerada empregatícia, em virtude dos objetivos educacionais do pacto instituído. (DELGADO, 2008, p. 323).

É justamente por isso que a função do estágio é tão importante e não pode ser frustrada, pois os objetivos do estágio em docência são de aprendizagem cuidando sempre para que não seja diferente desta, pois se assim acontecer, estaremos diante de uma relação de emprego, com todos os requisitos preenchidos, quais sejam: pessoalidade, onerosidade, subordinação, não eventualidade, pessoa física.

Quanto às atividades realizadas pelo estagiário na parte concedente, estas serão idênticas as realizadas pelos empregados da empresa que atuam na mesma área de conhecimento do estagiário. Desta forma entende Mascaro (2011) que o estágio, como prática que é, só pode ser realizado por intermédio do trabalho, e que este é igual para o empregado e o estagiário, diferindo-se ambos apenas por uma questão de grau. 
Religare, ISSN: 19826605, v.15, n.1, agosto de 2018, p.174-196.

Neste caso Martins (2012), diz que essa natureza do contrato de estágio é civil, tendo como principais características as seguintes: solenidade, por ser obrigatoriamente tácito; pessoalidade, pelo fato de sua anuência ser em virtude de ser um estudante uma das partes; de trato denominado sucessivo, pois é feito diariamente até ter o seu encerramento ocorrido; tripartite, por ser composto necessariamente de três partes (estagiário - unidade concedente - unidade de ensino); oneroso, no caso de ser estágio não vinculado; subordinariedade, devido ao fato do estudante ter deveres a serem cumpridos por ordens referidas a ele, tanto no caso da unidade concedente, como pela unidade de ensino.

\subsection{As concepções de estágio}

Segundo as elucidações de Sobrinho (2008), o contrato de estágio é estabelecido por três tipos de concepções.

No intuito de que tenhamos uma melhor compreensão das disciplinas da prática de ensino Estágio Supervisionado é necessária a observação de como se dá a gênese pedagógica que achamos estar implicitamente alocada na maneira em que se forma e treina-se professores em atividades práticas.

No nosso país, vemos quase que sempre, foi uma importância dada a profissionais internacionais, dos quais terminamos adotando suas teorias, métodos, formas de pensar e sugestões. Só que, não indagamos muitas vezes, se aquele método foi ou será compatível com nossa estrutura, com nossas possibilidades e principalmente com nossas características intrínsecas, e nos limitamos há apenas copiar um modelo, reproduzindo de forma um pouco insensata um padrão. Em uma reforma implantada em 1890 na Escola Normal em São Paulo, a prática de ensino indispensável era considerada deveras importante, mas o primeiro olhar que temos que ter, é de que a observância do princípio da ligação pedagógica tem de ser seguido, pois é ele que reza que o estágio é um ato educativo com finalidade pedagógica, que visa apresentar ao estudante a aplicação da teoria trabalhada em sala de aula; o princípio seguinte é o da adequabilidade, e está ligado intimamente ao anterior e determina que a 
Religare, ISSN: 19826605, v.15, n.1, agosto de 2018, p.174-196.

atividade do estágio precise ser alinhada à uma formação profissional que tenha sido escolhida pelo aluno e precisa ter consonância com o plano de curso, além do mais a instituição concedente precisa oferecer instalações que possuam maneiras de propiciar ao educando atividades de aprendizagem social, profissional e cultural.

Vejamos o entendimento que nos é trazido pelos escritos segundo Cassar (2010, p. 319):

Considera-se estagiário o estudante que, sem vínculo de emprego, presta serviços a uma pessoa jurídica, que lhe oferece um procedimento didático-profissional, que envolve atividades sociais, profissionais e culturais, através da participação em situações reais de vida e de trabalho, sob a coordenação da instituição de ensino, estágio curricular.

Por fim, vamos ter a última concepção, que é a de rendimento. Esta concepção vai ter a sua realização intimamente ligada à realização e efetivação dos outros princípios mencionados antes, pois estabelece que o estágio deva ter um caráter efetivo e eficiente no que tange ao cumprimento da diretriz de complementação do ensino e de qualificação do estudante.

\section{O estágio e seus requisitos}

Segundo dispõe Sobrinho (2008), o estágio pode ser de duas naturezas, as quais sejam objetiva e subjetiva. A primeira se remete a questão de: O que se exige para poder celebrar o estágio? A segunda descrição ocorre quando fazemos a pergunta: Quem pode celebrar o estágio?

\subsection{Requisitos objetivos}

São características específicas de cunho formador que aos serem transfiguradas, modifica a natureza de cunho pedagógico do estágio que é a observação e aprendizado por parte do estudante. Estes objetivos são bem claros 
Religare, ISSN: 19826605, v.15, n.1, agosto de 2018, p.174-196.

quanto à metodologia que deve ser empregada por parte dos orientadores e inclusive são estabelecidos por lei, e valem também para o ER e consta mais

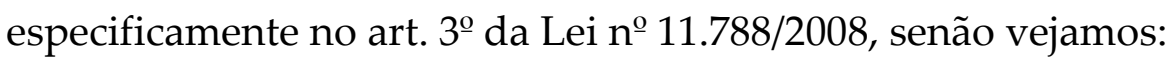

Art. 3o O estágio, tanto na hipótese do $\S 1$ 1o do art. 2o desta Lei quanto na prevista no $\S 2$ o do mesmo dispositivo, não cria vínculo empregatício de qualquer natureza, observados os seguintes requisitos:

I - matrícula e frequência regular do educando em curso de educação superior, de educação profissional, de ensino médio, da educação especial e nos anos finais do ensino fundamental, na modalidade profissional da educação de jovens e adultos e atestados pela instituição de ensino;

II - celebração de termo de compromisso entre o educando, a parte concedente do estágio e a instituição de ensino;

III - compatibilidade entre as atividades desenvolvidas no estágio e aquelas previstas no termo de compromisso.

$\S 1$ o $\mathrm{O}$ estágio como ato educativo escolar supervisionado, deverá ter acompanhamento efetivo pelo professor orientador da instituição de ensino e por supervisor da parte concedente, comprovado por vistos nos relatórios referidos no inciso IV do caput do art. 7o desta Lei e por menção de aprovação final.

$\S 2$ o O descumprimento de qualquer dos incisos deste artigo ou de qualquer obrigação contida no termo de compromisso caracteriza vínculo de emprego do educando com a parte concedente do estágio para todos os fins da legislação trabalhista e previdenciária.

Esses requisitos são indispensáveis quanto à sua aplicação no estágio e a validade do estágio depende dos mesmos. A não observação quanto ao cumprimento de um deles ou de todos eles trará como consequência irremediável a má formação, que acarretará na formatação de um professor de Ensino Religioso sem qualquer comprometimento com o senso crítico, para a nossa sociedade brasileira e em casos mais sérios podendo chegar na mudança do estágio em vínculo empregatício, o que seria totalmente complicado para o futuro da profissão docente no país. 
Religare, ISSN: 19826605, v.15, n.1, agosto de 2018, p.174-196.

\subsubsection{Matricula e comparecimento regular}

É importante entendermos que a validade do estágio esteja vinculada a matrícula por parte do aluno em um dos tipos estabelecidos pela lei. Além do que é preciso que o estagiário esteja matriculado e frequentando efetivamente as aulas. Essa verificação deste requisito é feita por parte da instituição de ensino à qual ele está vinculado, mas é importante também que a instituição também veja em que data se dará o término de seu curso. O outro aspecto importante que não pode deixar de ser observado é a compatibilidade de horários entre o período de estágio e o período de aulas do estagiário, que de forma alguma poderão coincidir, bem como a previsão máxima de carga horária que não poderá ser superada.

\subsubsection{Aliança entre o educando, a parte concedente do estágio e a instituição de ensino pelo Termo de Compromisso}

Com a nova lei de estágio, tornou-se indispensável entre as partes a celebração do termo de compromisso de estágio logo no início do mesmo, evitando assim dores de cabeça para a escola em uma possível visita de um representante do Ministério do Trabalho e Emprego.

O Ministério do Trabalho e Emprego consta de uma cartilha na qual ele explica justamente a importância do cumprimento dos requisitos legais na celebração do termo de compromisso, por ambas as partes, bem como do pagamento de bolsa ou outra forma prestação pecuniária se houver, auxíliotransporte, fornecimento do recesso no período de vigência do estágio, atitudes que dão ensejo para rescisão do termo de compromisso de estágio, vigência do estágio, carga horária do estagiário, horário de realização de atividades do estágio, identificação das partes, responsabilidades/obrigações de cada uma das partes, etc. 
Religare, ISSN: 19826605, v.15, n.1, agosto de 2018, p.174-196.

\subsubsection{A compatibilização do estágio à formação escolar do estagiário}

É de notório saber que, para que haja crescimento profissional do estagiário, não apenas no Ensino Religioso, que as funções exercidas pelo estagiário no estágio guardem ligação direta com o plano pedagógico do curso feito pelo estagiário. Só assim estaremos dando mais um pequeno passo na formação que queremos para o professor de ER. Nesses casos o estágio deve ser desenvolvido dentro da área específica para cada estudante.

No intuito de que não haja o descontrole e a desvirtuação do fim para o qual o Estágio foi criado, é deveras necessário que neste momento seja feito um acompanhamento do professor que tem a função de orientador na instituição de ensino. Também é necessário que haja entidades por parte das entidades de ensino superior e dos estabelecimentos escolares onde se passa o um engajamento no sentido de corroborar com a uma formação do estagiário, que o professor do Ensino Religioso da unidade escolar se empenhe em ajudar o estagiário, se permitindo também a absolver novas práticas e novos saberes. Os profissionais das entidades superiores são indicados no momento da celebração do estágio e serão eles que, geralmente ficarão incumbidos de no caminhar do estágio darem vistos nos relatórios apresentados pelos estagiários, no caso os estudantes da graduação em Ciências das Religiões.

\subsection{Requisitos subjetivos}

Em conformidade com o que foi dito anteriormente o estágio é uma relação triangular - como pode ser observado na celebração do termo de estágio - em que tendo em vista a obrigatoriedade da presença do estagiário na ponta da relação, mas também da instituição concedente e da instituição de ensino superior, caracterizando-se assim o contrato de estágio.

Não há como fugir da realidade de que o estagiário é necessariamente um estudante, e que este precisa se inserir, ou estar inserido, em uma das modalidades de ensino as quais sejam: aluno de educação em instituição de 
Religare, ISSN: 19826605, v.15, n.1, agosto de 2018, p.174-196.

ensino superior, de educação especial, dos anos finais do ensino fundamental, educação para jovens e adultos, da educação profissional, de ensino médio. Além disso, a Lei 11.788/2008 permite aos jovens que por algum motivo de ordem social como violência no lar, gravidez na adolescência, desigualdade financeira, abandono ou evasão e que não tiveram a oportunidade de terminarem seus estudos na idade certa, ou cursam supletivo, o direito de serem estagiários, bem como o estrangeiro que em alguma dessas situações mencionadas esteja em território brasileiro efetuando seus estudos de forma regular.

É importante saber que a legislação específica não determina idade mínima para o início das atividades como estagiário, tarefa essa que vem a ser desempenhada pela Constituição Federal de 1988, que no art. $7^{\circ}$, par. XXXIII, que é taxativa ao dizer que os menores de dezesseis anos não podem exercer nenhum tipo de trabalho, exceto na condição de aprendiz, vejamos então:

Art. $7^{\circ}$ São direitos dos trabalhadores urbanos e rurais, além de outros que visem à melhoria de sua condição social:

(...)

XXXIII - proibição de trabalho noturno, perigoso ou insalubre a menores de dezoito e de qualquer trabalho a menores de dezesseis anos, salvo na condição de aprendiz, a partir de quatorze anos.

Outro ponto importante é que a condição de estagiário não se perpetuará com o encerramento do curso de Ciências das Religiões. É normal que ao ter a conclusão de seu curso concretizada o estagiário se desvincule do cargo que exerce. Permanecendo, no entanto a relação de aprendiz deixará de existir e passará a se configurar relação de emprego.

Outro requisito subjetivo tem a ver com o fato de que as instituições de ensino podem ser de natureza públicas ou privadas e o seu dever no acompanhamento das atividades, bem como dos alunos para comprovar a execução do projeto pedagógico, são atividades desempenhadas no estágio e que devem estar de acordo com o próprio projeto pedagógico. 
Religare, ISSN: 19826605, v.15, n.1, agosto de 2018, p.174-196.

\subsection{Espécies de Estágio}

Extrairemos do artigo $2^{\circ}$, da lei $\mathrm{n}^{\mathrm{o}}$ 11.788/2008, essa classificação, que estipula duas espécies de estágio, que se diferenciam quanto à sua obrigatoriedade, as quais são: o Estágio obrigatório e Estágio não obrigatório. Essa diferença só é, no entanto percebida se partirmos para uma análise do projeto pedagógico apresentado pelo curso em questão.

Reconhecemos, entretanto, que se trata de estágio obrigatório se o mesmo é uma determinação explícita do projeto pedagógico do curso, situação na qual um cumprimento mínimo de carga horária passa a ser pré-requisito indispensável na expedição e obtenção do diploma por parte do estagiário. Nesse caso existe uma quantidade mínima de horas que deve ser observada, além do que existe um compromisso de fornecimento de relatórios do estágio para com na qual o estagiário é aluno de graduação.

Assim dito há ainda outra modalidade que é a de cunho não compulsório, em que é o estágio não obrigatório, ou seja, que é desenvolvido como atividade de natureza facultativa, caso este em que o estudante o faz podendo ou devendo ser remunerado.

\section{A estruturação da identidade profissional do ser professor do ensino religioso (er)}

O Fenômeno Religioso por muitos séculos está presente na vida social, política e econômica nas mais diversas sociedades. A educação faz o indivíduo refletir sobre os acontecimentos reais da vida, onde a religião é mencionada, tornando-os críticos, inovadores e contextualizados de saberes sobre as expressões religiosas. É nos limites das escolas que encontramos uma diversidade cultural religiosa fora da normalidade, muito embora as tradicionais expressões religiosas ainda estejam muito presentes. A escola é parte fundamental para que essa nova área do saber torne fácil a leitura do fenômeno religioso, oferecendo uma linguagem clara dos conteúdos acadêmicos e capaz de 
Religare, ISSN: 19826605, v.15, n.1, agosto de 2018, p.174-196. fazer o indivíduo refletir sobre os valores incomuns da diversidade cultural presente na sociedade.

Nos estudos acerca do fenômeno religioso é possível deparar-se ainda com um desafio de separar o que propõem os conhecimentos produzidos na área das Ciências das Religiões e os conhecimentos no campo da Teologia. O que existe hoje, é que muitos professores compreendem o Ensino Religioso como algo relacionado única e exclusivamente à teologia ou parecido com ela, pois ainda estão enraizados nesses modelos.

Segundo Silva (2011), um bom número de professores de ensino religioso acredita, ainda hoje, que ensinar é transmitir conhecimentos relevantes de sua doutrina e educação religiosa, sendo assim, a principal responsabilidade destes professores, de acordo com essa concepção, é a de serem grandes conhecedores dos assuntos relativos aos conteúdos doutrinários e confessionais de que vão tratar, com erudição, viabilizando o processo de transferência destes conhecimentos para os alunos da forma mais objetiva e clara possível. Portanto, o modelo catequético e confessional conduz o professor de ensino religioso a uma prática pedagógica tradicional. $\mathrm{O}$ autor menciona ainda que muitos são os professores de ER que compreendem a elaboração do saber a partir do conhecimento da própria religião que confessa, abandonando o espaço voltado para o conhecimento e tornando-o uma extensão dos lugares sagrados, esses sim devem ser confessionais. Não podemos negar a religião como objeto de estudo, pois se trata de uma necessidade humana e faz parte da sua história, porém estamos percorrendo um momento em que essa área do saber não está conectada apenas a uma expressão religiosa, mas a uma diversidade; por isso não devemos através da educação tratar os estudos como algo particular e confessional. O professor enfrenta um grande desafio em fazer essa separação. Ora, se o professor sente dificuldade de fazer essa diferenciação, que dirá o Estagiário que passa a frequentar e conhecer a realidade escolar do Ensino Religioso, apenas nos últimos semestres dos Cursos de graduação em Ciências das Religiões. 
Religare, ISSN: 19826605, v.15, n.1, agosto de 2018, p.174-196.

Uma formação deve propor um processo que confira ao docente conhecimentos, habilidades e atitudes para criar profissionais reflexivos ou investigadores. O eixo fundamental do currículo de formação do professor é o desenvolvimento de instrumentos intelectuais para facilitar as capacidades reflexivas sobre a própria prática docente, cuja meta principal é aprender a interpretar, compreender e refletir sobre a educação e a realidade social de forma comunitária (IMBERNÓN, 2011, p. 58).

Essa gama de atribuições e regras direcionadas ao professor estão relacionadas com as regras de ensino-aprendizagem nas diversas instituições educacionais, pelo menos é o que vemos através dos projetos políticos pedagógicos, dos planos de ensino, das metas traçadas e dos objetivos a serem alcançados pelos modelos que lhes são apresentados durante o seu período de crescimento e maturamento profissional.

Segundo Hans-Jurgen Greschat,

\begin{abstract}
A palavra "religião" serve para especialistas de diversas disciplinas, embora nem sempre - e nem em todos os lugares - denomine a mesma coisa. O que um termo quer dizer depende de sua definição. O esclarecimento do seu significado, pois, deve informar o que caracteriza "religião" - mas aí a dificuldade. Embora existam muitas definições de religião - algumas centenas, presumidamente, até hoje não se chegou ao resultado esperado. Não há definição que não seja rejeitada por, pelo menos uma pessoa (GRESCHAT, 2005, p. 20).
\end{abstract}

A licenciatura em Ciências das Religiões é uma das ferramentas que contribui na formação e capacitação do professor, através de conteúdos pedagógicos necessários para a diversidade cultural religiosa presente na sociedade, buscando ser imparcial nos assuntos religiosos, não permitindo atos de intolerância ou atos violentos a um indivíduo pela escolha da sua religião, tornando tanto o graduando da licenciatura, quanto o educando consciente que a única verdade é o que acreditamos e não como um todo. Nesse contexto vemos a importância do Estágio Supervisionado no Ensino Religioso, pois é através dele 
Religare, ISSN: 19826605, v.15, n.1, agosto de 2018, p.174-196.

que levaremos aos graduandos experiências reais de sua prática, com a observação de tabus, paradigmas e desafios a serem superados.

\subsection{A Perspectiva do Estágio Supervisionado (ES) no curso de Ciências das Religiões na UFPB}

A legislação que regulamenta o Estágio Supervisionado do Curso de Ciências das Religiões, da modalidade Licenciatura, do Centro de Educação, do Campus I da UFPB, é a Resolução CGCR 02/2011.

O Artigo $2^{\circ}$ da Resolução afirma que o Estágio Supervisionado é um componente curricular teórico-prático do processo de ensino-aprendizagem, de conteúdo obrigatório, realizado ao longo do curso, de modo a assegurar aos graduandos experiência de exercício profissional em ambientes escolares, ampliar as atitudes éticas, fortalecer os conhecimentos e competências, combater os preconceitos e inibir qualquer tipo de proselitismo, tendo assim como objetivo geral propiciar ao educando o conhecimento da história, legislação e prática pedagógica no âmbito do componente curricular do ensino fundamental e médio denominado de "Ensino Religioso".

No Artigo 3oㅡ, São descritos os objetivos específicos do Estágio Supervisionado, que são:

I - Proporcionar aos educandos contato com a realidade educacional e o funcionamento das entidades educacionais, bem como da comunidade;

II - Proporcionar ao educando oportunidades de desenvolver suas competências para analisar situações e propor mudanças no ambiente educacional;

III - Formar profissionais inovadores, capazes de usar e aprimorar modelos, métodos, processos e tecnologias educacionais.

Como parte do processo de compreensão referente ao Estágio Supervisionado do Curso de Graduação em Ciências das Religiões (CGCR), é possível visualizar os chamados componentes teóricos (CT), componentes 
Religare, ISSN: 19826605, v.15, n.1, agosto de 2018, p.174-196.

teórico-práticos (CTP) e componentes práticos $(\mathrm{CP})$. Nesse sentido, o documento em si procura buscar iniciativas que contemplem no contexto dos estágios a relação entre "teoria e prática", conforme vimos anteriormente.

Assim, o Artigo 4ํ. afirma:

Art. $4^{\circ}$. O ES do Curso de Graduação em Ciências das Religiões (CGCR) compreende componentes teóricos (CT), componentes teórico-práticos (CTP) e componentes práticos $(\mathrm{CP})$, assim distribuídos:

ES-I (CT): História do Ensino Religioso (ER) no Brasil;

ES-II (CT): Legislação do ER no Brasil e no mundo;

ES-III (CTP): Oficina de Teatro como instrumento didático do ER;

ES-IV (CTP): Danças circulares como instrumento didático do ER;

ES-V(CTP): Música sacra como instrumento didático para o ER;

ES-VI (CP): Observação da regência do ER na rede pública e particular; $\quad$ ES-VII $(\mathrm{CP})$ : Observação participante junto ao professor regente do componente ER na rede pública e particular.

Na Resolução, a distribuição entre os aspectos teóricos e práticos e suas possíveis implicações sobre as dinâmicas relativas aos desdobramentos no contexto de sala de aula, são detalhados nos Artigos 5ํ․, $6^{\circ}$. e 7º․, como veremos a seguir:

Art. $5^{\circ}$. Para efeito de distribuição da carga horária teórica e prática fica estabelecido:

I - O ES-I e o ES-II serão teóricos;

II - Do ES-III ao ES-V a carga horária será equitativa entre teoria e prática;

III - O ES-VI e ES-VII serão totalmente práticos, realizados nas escolas da rede pública e particular.

Art. 6․ Os Estágios de I a V serão avaliados de acordo com o plano de curso de cada componente curricular específico.

Art. $7^{\circ}$. Os ES VI e VII deverão respeitar as seguintes diretrizes: I - Serão individuais;

II - Estarão sob a supervisão da Coordenação de Estágio (CdE);

III - O plano de trabalho do estagiário será previamente aprovado pelo NDE; 
Religare, ISSN: 19826605, v.15, n.1, agosto de 2018, p.174-196.

IV - O Relatório do estágio será avaliado de acordo com os objetivos específicos estabelecidos pelo Art. 3 desta Resolução, considerando o produto final e o processo de construção.

No Artigo. $8^{\circ}$, o mesmo trata sobre a Coordenação de Estágio (CdE), onde será composta por um Coordenador indicado pelo Colegiado do Curso de Ciências das Religiões e por professores do Centro de Educação da UFPB.

No Artigo $12^{\circ}$, descreve-se as competências relativas à Coordenação de Estágio, conforme segue:

I - Coordenar o planejamento e a avaliação das atividades de estágio; II - Entrar em contato com os estabelecimentos educacionais concedentes de estágio para análise das condições específicas, tendo em vista a celebração de convênios e acordos, quando for o caso; III - Providenciar os termos de compromisso a serem firmados entre alunos e instituições concedentes de estágio; IV - Organizar e manter atualizado o sistema de documentação e cadastramento de estágio, registrando as instituições envolvidas e o número de estagiários de cada período de estágio; V - Orientar o estagiário na elaboração do plano de estágio; VI - Indicar fontes de pesquisa para solucionar as dificuldades encontradas; VII - Manter contatos periódicos com o gestor e com o docente de classe das instituições concedentes de estágio, buscando o bom desenvolvimento das atividades, intervindo sempre que necessário.

O Artigo 13ํ, faz referência ao que de fato compete ao estagiário:

I - Observar os regulamentos e exigências do campo de estágio. II - Elaborar o plano de estágio sob orientação da CdE; III Permanecer no estágio até o final do tempo regulamentado; IV Realizar e registrar as atividades previstas no plano de estágio; V - Justificar com antecedência ao Coordenador de Estágio e ao professor da escola, quando ocorrer sua ausência na atividade prevista no plano de estágio; VI - Repor as atividades cuja justificativa de ausência tenha sido aceita pelo professor da escola e pelo Coordenador de Estágio; VII - Participar das atividades determinadas pela CdE; VIII - Entregar na CdE, em data previamente fixada, o relatório final de estágio; IX - Manter atitude ética, responsável, isenta de preconceito e de proselitismo, desejável ao desempenho profissional, nas atividades desenvolvidas durante o estágio. 
Religare, ISSN: 19826605, v.15, n.1, agosto de 2018, p.174-196.

\section{Considerações Finais}

É de notória percepção que ao passar dos tempos a legislação que temos no Brasil modificou-se e avançou bastante trazendo diversas inovações para a prática do Estágio Supervisionado. O que se tem visto claramente é a ampliação e destaque da importante relação "teoria e prática" como processos indissociáveis e inegociáveis dentro das diferentes dinâmicas exercidas pelo estudante no seu Estágio Supervisionado. Há com certeza, em alguns momentos, um desvirtuamento quanto à relação ao estágio em si, ocorridos durante algum tempo no nosso país, mas que hoje já é bem menor se comparado há algumas décadas atrás. Entretanto, vale ressaltar, que existe ainda algumas deficiências como as burocracias enfrentadas na hora de conseguir um estágio como: a falta de vagas em algumas escolas, a falta de ambientes condizentes com o valor dos profissionais em geral e da educação especificamente, uma enorme parcela ainda de estágios informais, onde não há nem mesmo o Termo de Compromisso de Estágio - formalidade mínima na concepção de um Estágio Supervisionado.

O Ensino Religioso hoje, apesar de recentes alterações feitas pelo Supremo Tribunal Federal (STF), traz uma nova proposta para o estudo do fenômeno religioso, que tem como base os dispositivos legais, que compreendem a todos os cidadãos como sujeitos de direitos, quanto ao fato de terem uma confissão religiosa ou não, tornando o Estado imparcial aos assuntos religiosos, portanto, não poderá nenhum indivíduo ser discriminado pela confissão religiosa escolhida. A sala de aula se torna um espaço importante para elaboração dessa nova área de conhecimento, a escola tem por obrigação proporcionar aos educandos e aos docentes um ensino que o faça compreender sua importância como cidadão e possibilite a discussão e socialização dos saberes. Verificar se os afazeres ali constam em de acordo com o plano de estágio e se o mesmo está contribuindo para a capacitação do estagiário.

É importante fazer uma avaliação semestral ou trimestral para ver se o requisito do estágio vem sendo cumprido, chamar à atenção da unidade concedente se ela não estiver cumprindo esses requisitos, etc. 
Religare, ISSN: 19826605, v.15, n.1, agosto de 2018, p.174-196.

É importante também que quem concede o estágio propicie ao estudante, na medida do possível, uma experiência próspera de troca de conhecimentos, para que o estágio não seja dotado apenas de uma experiência de caráter burocrático que não acrescentará em nada em sua vida pós universidade.

Por outro lado, verifica-se a importância do estágio na capacitação e profissionalização docente em sua fase inicial, através de saberes que são conquistados de uma maneira que levem em consideração a teoria, mas da mesma forma um conhecimento prático. A licenciatura em Ciências das Religiões é uma das ferramentas que contribui na formação e capacitação, através de conteúdos pedagógicos necessários para a diversidade cultural religiosa presente na sociedade, buscando ser imparcial nos assuntos religiosos, não permitindo atos de intolerância ou atos violentos a um indivíduo pela escolha da sua religião, tornando o educando consciente que a única verdade é o que acreditamos e não como um todo. Nesse contexto vemos a importância do Estágio Supervisionado no Ensino Religioso, pois é através dele que levaremos aos graduandos experiências reais de sua prática, com a observação de tabus, paradigmas e desafios a serem superados.

É interessante que observemos também que os professores que já lecionam há algum tempo, procurem a cada dia melhorar, rever suas práticas de ensino, de acordo com as realidades que aparecem no decorrer de seus caminhos. Esses olhares sensíveis a cada realidade, também vão permitir que os graduandos no Ensino Religioso construam características que vão facilitar a efetivação de suas competências e a efetuação dos objetivos conforme a nova versão da Base Nacional Comum Curricular (BNCC).

\section{Referências}

BRASIL. Constituição da República Federativa do Brasil de 1988. Disponível em:

$<$ http://www.planalto.gov.br/ccivil_03/constituicao/constituicao.htm>. Acesso em: 20 abr. 2018. 
Religare, ISSN: 19826605, v.15, n.1, agosto de 2018, p.174-196.

BRASIL. Lei no 9.394, de 20 de Dezembro de 1996. Disponível em:< http://www.planalto.gov.br/ccivil_03/Leis/L9394.htm>. Acesso em: 26 abr. 2018.

.Decreto-Lei no 5.452 , de $1^{0}$ de maio de 1943 - Consolidação das Leis do trabalho. Atualizada até 29 de dezembro de 2012. Disponível em: $<$ http://www.planalto.gov.br/ccivil_03/decreto-lei/del5452.htm>. Acesso em: 20 mai. 2018.

.Decreto no 87.497, de 18 de agosto de 1982. Disponível em: <http://www.planalto.gov.br/ccivil_03/decreto/d87497.htm>. Acesso em: 20 mai. 2018.

.Lei no 8.906, de 4 de julho de 1994. Disponível em: <http://www.planalto.gov.br/ccivil_03/leis/18906.htm>. Acesso em: 20 fev. 2018.

.Lei $\mathrm{n}^{\mathrm{o}}$ 11.788, de 25 de setembro de 2008. Disponível em: $<$ http://www.planalto.gov.br/ccivil_03/_ato2007010/2008/lei/111788.htm>. Acesso em: 20 mar. 2018.

Texto referência para a Audiência Pública sobre as Diretrizes Curriculares Nacionais para o curso de graduação em Ciências da Religião. Conselho Nacional de Educação. Disponível em: http://portal.mec.gov.br/index.php?option=com_docman\&view=download\&ali as=95661-texto-referencia-dcn-ciencias-da-religiao\&category_slug=setembro2018-pdf\&Itemid=30192 Acesso em Novembro de 2018.

BERNARDY, Katieli; PAZ, Dirce Maria Teixeira. Importância do estágio supervisionado para a formação de professores. Disponível em: $<$ http://www.unicruz.edu.br/seminario/downloads/anais/ccs/importancia\%20do \%20estagio\%20supervisionado\%20para\%20a\%>. Acesso em 15 maio 2018.

CASSAR, Vólia Bonfim. Direito do Trabalho. 4. ed. Niterói: Impetus, 2010.

DELGADO, Maurício Godinho. Curso de Direito do Trabalho. 7. ed. São Paulo: LTr, 2008.

FILHO, Antônio. P. O Estágio Supervisionado e sua importância na formação docente. Revista Partes. 2010. Disponível em: $<$ http://www.partes.com.br/educacao/estagiosupervisio>. Acesso em: 20 abr. 2015.

GIUMBELLI, E. A Religião nos limites da simples educação: notas sobre livros didáticos e orientações curriculares de ensino religioso. Revista de Antropologia da USP, São Paulo, v. 53, n. 1, 2010. Disponível em:<http://www.revistas.usp.br/ra/article/view/27345>. Acesso em 09 de jul. 2018.

GRESCHAT, Hans-Jurgen. Constituintes da Ciência da Religião: cinco ensaios em prol de uma disciplina autônoma. São Paulo: Paulinas, 2006. p. 9-28, 63-78. 
Religare, ISSN: 19826605, v.15, n.1, agosto de 2018, p.174-196.

O que é ciências das religiões? Tradução de Frank Usarski. São Paulo: Paulinas, 2005. (Coleção repensando a religião).

GUEDES, Thiago Rafael Soares de Souza. Questões a respeito do Estágio Supervisionado e sua importância como prática pedagógica na formação docente. 2014. 44 p. Monografia (Especialização em Fundamentos da Educação: Práticas Pedagógicas Interdisciplinares) - Universidade Estadual da Paraíba UEPB, João Pessoa.

GUEDES, Thiago Rafael Soares de Souza. Importância do Estágio Supervisionado na formação do professor de Ensino Religioso. 2015. 41p. Monografia (Curso de graduação em Ciências das Religiões) - Universidade Federal da Paraíba - UFPB, João Pessoa.

IMBERNÓN, Francisco. Formação docente e profissional: formar-se para a mudança e a incerteza. [tradução Silvana Cobucci Leite]. 9. ed. São Paulo: Cortez, 2011. (Coleção questões da nossa época; v. 14).

JANUARIO, Gilberto. O Estágio Supervisionado e suas contribuições para a prática pedagógica do professor. In: SEMINÁRIO DE HISTÓRIA E INVESTIGAÇÕES DE/EM AULAS DE MATEMÁTICA, 2, 2008, Campinas. Anais... II SHIAM. Campinas: GdS/FE-Unicamp, v. único. p. 1-8. 2008.

MARTINS, Sérgio Pinto. Direito do Trabalho. 28. ed. São Paulo: Altas, 2012.

MOACYR, Primitivo. A Instrução pública no Estado de São Paulo. São Paulo. Nacional, 1942. 2 v.

NASCIMENTO, Amauri Mascaro. Curso de direito do trabalho: relações individuais e coletivas de trabalho. 26. ed. São Paulo: Saraiva, 2011.

PASSOS, J. D. Ensino religioso: construção de uma proposta. São Paulo: Paulinas, 2007. (Coleção temas do ensino religioso).

PIMENTA, S. G. O estagio na formação de professores: unidade, teoria e prática? 3. ed. São Paulo: Cortez, 1997.

PIMENTA, S. G./ LIMA, M. S.L. Estagio e docência. São Paulo: Cortez, 2008.

SILVA, Marinílson Barbosa Da. Em busca do significado do ser professor de Ensino Religioso. João Pessoa: Editora Universitária UFPB, 2011. (Coleção Ciências das Religiões).

SOBRINHO, Zéu Palmeira. O contrato de estágio e as inovações da Lei 11.788/2008. Revista Ltr. Legislação do Trabalho, v.10, p.1173-1188, 2008. Disponível em: http:<//www.amatra21.org.br/2013/_up/downloads/f2_ee0171acdfea974530e259 eea901eab0. pdf>. Acesso em: 16 mar. 2018. 